\title{
PERSONAL CHARACTERISTICS AND PERFORMANCE OF PILOT IN THE INDONESIAN NAVAL AVIATION CENTER: META-ANALYSIS STUDY
}

\section{HADI PRIYONO ${ }^{1}$, SRI ISWATI ${ }^{2}$, DIMAS AGUNG TRISLIATANTO ${ }^{1}$, MOSES GLORINO RUMAMBO PANDIN ${ }^{*}$}

${ }^{1}$ Doctoral Student of Human Resource Development Study Program, Postgraduate School, Universitas Airlangga, Surabaya, Indonesia

${ }^{2}$ Faculty of Economy and Business, Universitas Airlangga, Surabaya, Indonesia

${ }^{3}$ Research Group on Disaster Resilience Management, Master of Disaster Management, Postgraduate School; Faculty of Humanities, Universitas Airlangga, Indonesia

\begin{abstract}
Facing the tasks and challenges going forward, a pilot of the Indonesian Naval Aviation Center was required to be brave in taking risks, especially in carrying out its main tasks, so it was expected that a pilot of the Indonesian Naval Aviation Center had intelligence, especially in finding appropriate solutions and alternatives to address every task challenges dynamics in situations that often changed quickly. The purpose of this study was to identify the personal character and performance that should be owned by the pilot of the Indonesian Naval Aviation Center. This research used a qualitative approach with a contextual and constructional meta-analysis study method. The results of this meta-analysis study concluded that in line with the essence of personal character that is defined as the personal aspects of a work that allows workers to achieve superior performance. These personal aspects include nature, emotive-motives, value systems, attitudes, knowledge, and skills, where the personal character would produce an optimal performance on a pilot of the Indonesian Naval Aviation Center.
\end{abstract}

Keywords: Personal, personal characteristics, performance, pilot, Indonesian Naval Aviation Center

\section{Introduction}

Since its birth, as an instrument of the state in the field of defence, the Navy has experienced certain changes along with changes in Indonesian society. Major changes due to the change of power from the New Order to the Reformation era, along with changes in values at the global level, also influenced changes in the role of the Indonesian Navy from the Pretoria army, namely the army involved and intervening in political life towards professional soldiers. Nevertheless, up to now many groups are still debating the nature of Indonesian National Army professionalism. In the current era of globalization of Industry 4.0 reform, the Navy is demanded to develop personality characteristics with leadership characteristics that are 
reliable, credible, and responsive to the challenges of increasingly heavy tasks and prioritizing professionalism in performance.

According to State Budget and Expenditure Budget data for 2002-2015, 5-7\% of the total expenditure of the State Budget is allocated to the defence sector annually. In 2006, defence accounted for $5.9 \%$ of the total State Budget. This figure crept up to $6.7 \%$ in 2012 and continued to crawl in the following year. The increase in the budget in the defence sector has reached three times from 2007 to 2013 , from IDR 30.7 trillion to IDR 81.8 trillion. The defence budget for the Indonesian National Army is used to invest in the defence and security sector so that national sovereignty is maintained, the political climate is safe, investment goes well, and finally, the economy is running as expected. However, unfortunately, research on accountability and performance in the military sector in Indonesia has not been widely circulated. Indonesian National Army needs research to be able to develop defence strengthening strategies both in terms of hardware and software. The human aspect is a software aspect that needs attention.

One of the efforts is through continuous learning orientation conducted by the pilot of the Indonesia Naval Aviation Center in particular because the meaning of learning is the development to gain new knowledge or the ability to produce behavior. A strong military pilot flight orientation learning will encourage someone to continue to improve their ability to support their work and provide the best results for their work (Cox et al., 2013). The learning process will increase the ability and knowledge capacity so that capabilities will increase if the members of the pilot unit increase their capabilities, it will be easy to be directed by the leader (Carretta et al., 2014).

Military pilot activities in units are divided into the program and non-program activities Chang, Lee, \& Lung, 2018). Furthermore, according to Castaneda (2007) program activities are training activities that have become unit programs with fixed and scheduled periods of the 
year, such as training activities that have been divided per quarterly period for both flight and other activities. In order to face the tasks and challenges going forward, a pilot of the Indonesian Naval Aviation Center is required to be brave in taking risks, especially in carrying out its main tasks, so it is expected that a pilot of the Indonesian Naval Aviation Center has intelligence, especially in finding appropriate solutions and alternatives to address every task challenges dynamics in situations that often change quickly. As a pilot of the Indonesian Naval Aviation Center, they are an example and role model for their members. They are required to have a sharp analytical power so that they can catalyse a dynamism the unit towards the achievement of the success of the main tasks of the unit, not stop thinking and innovating for the progress and success of the unit or organization.

If there are mistakes in work (disciplinary violations) that they have committed or which are their responsibility, they will accept the consequences ranging from disciplinary action to the violation which then affects their performance evaluation which can affect their career path in the future (Packard, 2019). On the other hand, there is the concept of the new professionalism introduced by Stepan, who views the military as a group that has and plays a comprehensive role in society and development (Robertson \& Putnam, 2008). Here, the role of the military is expanded to deal with threats from outside and within the country, especially in underdeveloped countries (Smith et al., 2016).

Many factors can affect the performance of pilots of the Indonesian Naval Aviation Center, such as training, esprit de corps, performance, personal characteristics, and teamwork. Implementation of training that has not been maximized, esprit de corps is considered immature, and personality traits that are not strong can lead to the performance of soldiers is not optimal (Rose et al., 2014). In addition, esprit de corps soul according to Smith et al. (2017) which has been fostered and fostered has not been maximally, also resulted in the performance of soldiers is still not optimal too. Based on these problems, the purpose of this study is to 
identify the personal characteristics and performance that should be owned by the pilot of the Indonesian Naval Aviation Center.

\section{Methodology}

\section{Research Approach and Design}

This research uses a qualitative approach with a contextual and constructional meta-analysis study method. Meta-analysis can also be conducted on various secondary data observational studies to produce conclusions from the merging of research results (Gogtay \& Thatte, 2017). According to Crocetti (2016), a systematic meta-analysis method for analysing and synthesizing results from independent studies, taking into account all relevant information through synthesis, researching, tabulating, and possibly integrating all relevant studies, metaanalysis enables more objective assessment, which can help to overcome uncertainties in original research, classic reviews, and editorial comments. There are types of synonyms for the meta-analysis used in the literature: overview, aggregate, synthesis, integration, and combining (Ahn \& Kang, 2018).

\section{Sampling Technique}

This study uses a library samples consisting of books or journals as data sources and takes some research on one topic that has been done and reported. By doing this, researchers can find out the strengths, weaknesses, weaknesses, or even errors of each study related to personal character and performance of pilots in the Indonesian Naval Aviation Center.

\section{Analysis Data Technique}

Meta-analysis can be said as a separate study. Subjects in the meta-analysis are the results of research that will be included in the meta-analysis. The systematic review process includes several stages that are aligned with primary research. Consists of problem formulation, sampling data collection, data analysis, interpretation, and presentation of results. 


\section{Results and Discussion}

\section{Personal Characteristic of Pilot: Measurements and Aspects}

Measurement of meta-analysis related to the personal character in this study uses Bloom's taxonomy. Bloom's Taxonomy is a concept of three hierarchical models that are used to classify behavioural development based on education, training, and development objectively according to Gao \& Kong (2016). The three aspect models are:

1.) Cognitive, namely the ability and activity of the brain to develop rational abilities. Cognitive includes aspects of knowledge, understanding, application, analysis, synthesis, and evaluation.

2.) Affective, which is material based on everything related to emotions such as appreciation, values, feelings, passion, interests, and attitudes towards things. Affective covers aspects of acceptance, responsiveness, judgment, organization, and character.

3.) Psychomotor, the domain that includes movement behavior and physical coordination, motor skills, and physical abilities of a person. These aspects include imitation, readiness, guided responses, mechanisms, seemingly complex responses, adaptation, and creation. Based on the above view, the researcher uses the conceptual definition of a series of individual activities of pilots of the Indonesian Naval Aviation in systematically increasing expertise and knowledge so as to be able to have professional performance in their fields.

The results of the meta-analysis are in line with the essence of personal character which is defined as the personal aspects of a worker that enables workers to achieve superior performance. These personal aspects include nature, emotive-motives, value systems, attitudes, knowledge, and skills. Competence will direct behavior, where the personal character will produce optimal performance (Maroco \& Ribeiro, 2013). Referring to the concept, not all 
personal pilot aspects of a worker are competencies. Only the personal aspects that drive pilot to achieve superior performance are his competencies (Marrón, 2018).

According to Donahue \& Kentle in Murray, Berkowitz \& Lerner (2019) divided the dimensions of personal character into five namely: openness to experience, conscientiousness, extraversion, agreeableness, and neuroticism (OCEAN). These are outlined in the following personal characteristics of pilots in the Indonesian Naval Aviation Center:

1.) Personality openness to experience or openness to life experiences, among others, full of new ideas, active imagination, clever and deep, like self-reflection, curious about many things, innovative, and artistic. While individuals with closed to experience personalities have the opposite characteristics that are not innovative, like something that is routine, practical, and tends to be closed.

2.) Personality conscientiousness or openness of the eyes and ears include: working hard, working according to plan, reliable, organized, doing work carefully and in detail, and tends to be diligent. Individuals with this personality are said to have high conscientiousness. Whereas individuals with low conscientiousness have personality: careless, lazy, disorganized, and unreliable.

3.) Personality extraversion or openness to others, among others: active speaking, full of energy, enthusiastic, strict, and certain personality, friendly, and sociable. Individuals with this personality are said to have high popularity.

4.) Agreeableness or openness to an agreement has a personality, among others: likes to work together, trustworthy, caring and kind to others, likes to help, selfless, forgiving, and does not like disputing with others. Individuals with these personalities are said to have high agreeableness.

5.) Neuroticism or openness to pressure has a personality, among others: often feel depressed, full of tension and worries, easily moody and sad, and easily agitated. 
Individuals with this personality are said to have unstable emotions. Conversely, individuals with stable emotions have personalities, among others: able to cope with stress well, not easily disappointed, calm intense situations, and not easily depressed. Military education and development in the Indonesian Naval Aviation Center, where the best military pilots do not only produce quality pilots in technical matters. A person who fully understands his abilities and also the limits of his own expertise knows very well about the limits of the ability of the aircraft flown, the experience he has, and always evaluates all risks (Bjerke et al., 2016). In the opinion of Gao \& Kong (2016), pilots must always be focused and alert, they must not lose focus for even a second. Discipline, consistent, and have good judgment when making decisions.

Pilots are also able to read the environment and appreciate it, and are firm in upholding regulations that flight safety is the main thing (Glicksohn \& Naor-Ziv, 2017). That is a good character that pilots must have everywhere. It is not only enough that a navy pilot soldier graduated from the Indonesian Naval Aviation School, where a prospective pilot is not only educated in technical matters but also in character development so that each individual is able to become a qualified pilot. The results of the meta-analysis related to personal characteristics of the pilot were also associated with an experience, temperamental traits, and aggression according to Makarowski et al. (2016) in the following: 


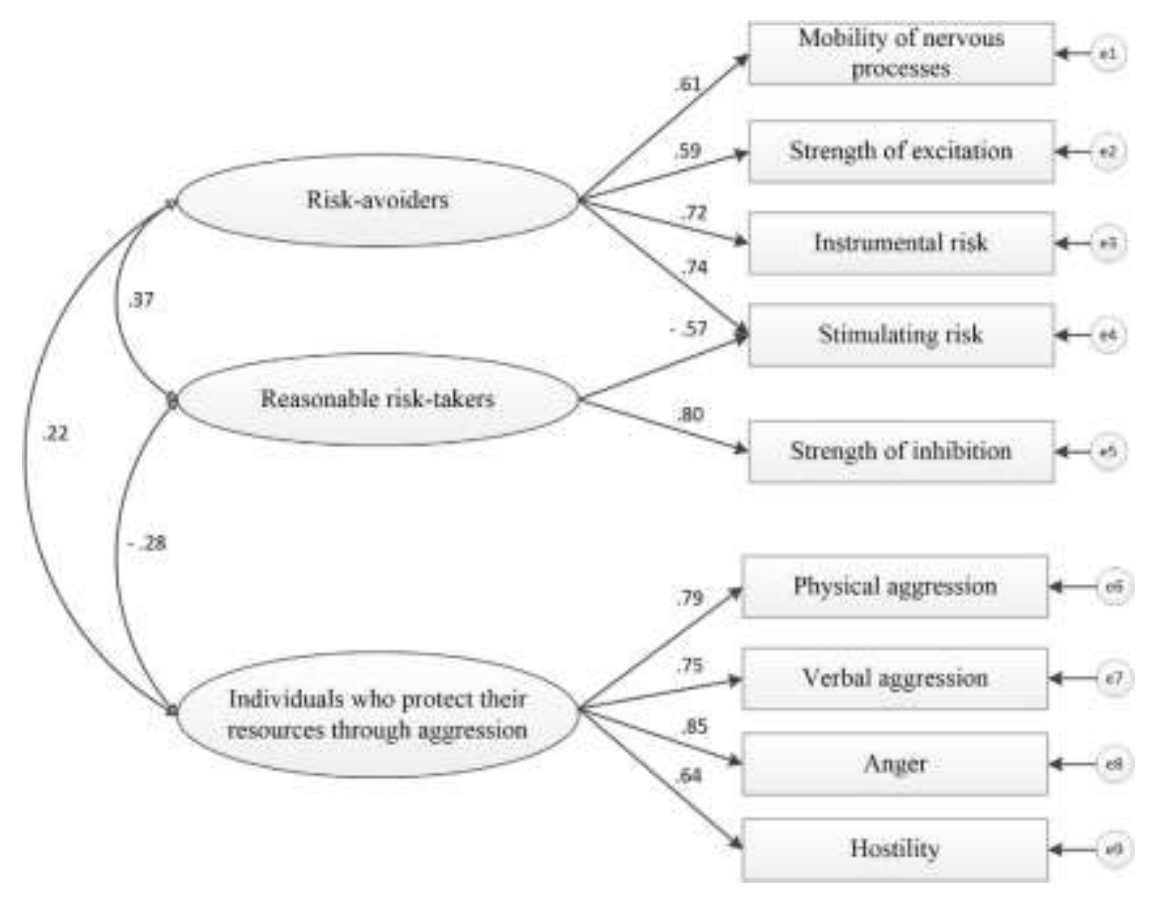

Figure 1: A path diagram for the three isolated factors (Source: Makarowski et al., 2016)

The research findings show that professional pilot do not form homogeneous groups. Cluster analysis can make it possible to identify three different sub-groups from each temperament, aggression, and risk examined. Related to the role of developing their personal characteristics in the midst of environmental agencies and community life, Rose et al. (2014) proposed the terminology of civilian control. Civil control is synonymous with democratic government, while military control is synonymous with a totalitarian government. Civil control is divided into subjective civilian control and objective civilian control. In subjective civilian control, the civil power tries to maximize power (including at the expense of other civil groups) and tries to attract the army into civilian affairs for its interests, both political and economic.

As for objective civilian control, what is trying to be maximized is military professionalism itself by upholding four main points, including 1.) High military professionalism and military officials' recognition of the limits of professionalism that are their field; 2.) Effective subordination from the military to political leaders who make key decisions about foreign and military policy; 3.) Recognition and approval of political leaders on 
professional authority and military autonomy; 4.) Consequently, the minimization of military intervention in politics and minimization of political intervention in the military (Rose et al., 2014).

\section{Pilot Performance of Indonesian Naval Aviation Center Based on Specification Behavior}

One of the problems on the airplane is the plane crash. The increase in accidents can be an indicator of flight operational readiness. An airplane crash is actually closely related to flight safety and is not solely the responsibility of the pilot himself but is influenced by one or more combined of the three main factors in aviation namely humans, engines, and media (Naikar \& Sanderson, 2001). Human factors include human readiness, namely the readiness of pilots and other crew members. The engine factor refers to the aircraft itself, while the media factor includes natural phenomena, namely weather conditions, terrain, altitude, and wind. The Federal Aviation Administration (FAA) concludes that there are 3 (three) main factors causing aircraft accidents, namely weather factors, technical factors, and human factors (Tangwe \& Shan, 2014).

Airplane crashes occur because of interactions between human factors and other factors causing accidents. The performance of pilots in the Indonesian Naval Aviation Center in terms of flight operations consisting of phases of time, phase of flight, location (terrain conditions), and weather for airplane crashes direct (direct effect) and also its influence on the pilot itself, in this case, is the effect on performance that could be the cause of an aircraft crash (indirect effect) (Judy \& Gollery, 2019). The consequences that must be faced by these pilots is that they must be able to learn and use aircraft systems, including survival efforts when facing system failure. The consequences will increase to the risk of stress for pilots when related to military objectives because, in addition to having to adapt themselves to the flight system, these 
pilots are also required to be able to survive to face various threats and risks according to military tasks (Tangwe \& Shan, 2014).

All of this has implications for the emotional state and personal behavior of the pilot of the Indonesian Naval Aviation Center. According to Young (2008), the existence of various kinds of demands and risks of heavy work that must be faced by military pilots shows the need for treatment so that military pilots can cope with high demands or workloads which can result in high work stress. The adverse effects of work stress experienced include low productivity, lack of creativity, reduced motivation, and influence in decision making (Smith et al., 2016). Though the right decision making and composure are one of the important factors of performance that must be owned by the pilot of the Indonesian Naval Aviation Center. Figure 2 below is the basic structure scheme of an airplane flight scenario that is driven optimally according to Tangwen \& Shan (2014):

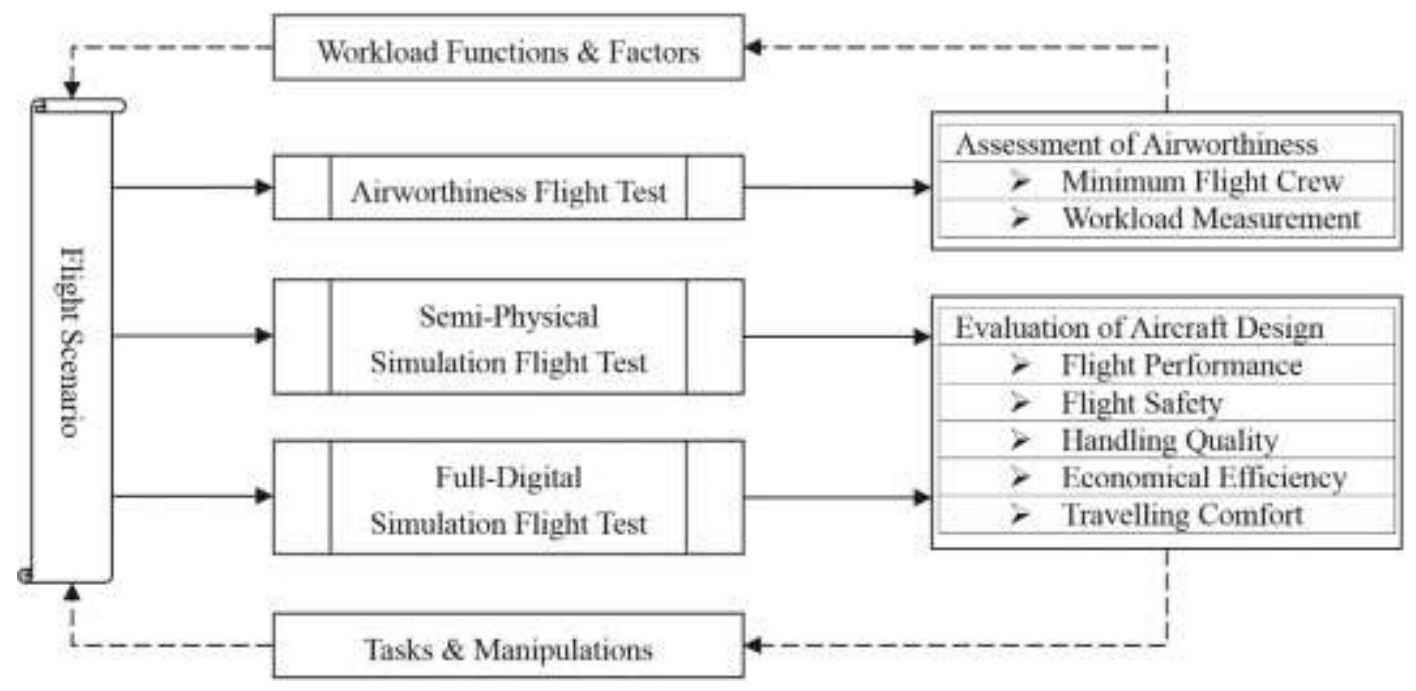

Figure 2: Theoretical basis of flight scenario (Source: Tangwen \& Shan, 2014)

All pilot soldiers who work in the Indonesian Naval Aviation Center are people who have above average intelligence because to become a pilot, he has gone through various tests, from academic tests, psychological tests, mental health tests, physical health tests, psychological tests, and mental tests and ideology. Each of these tests has a high standard, 
where a pilot of the Indonesian Naval Aviation Center would have gone through and passed the tests, meaning he was intelligent. The pilot's performance and personal characteristics are different-matter but have a unique relationship. Smart, humble, and virtuous pilots are what the Indonesian Naval Aviation Center hopes for.

Military aviation operations are risk-laden activities that can result in accidents or incidents. Accidents and incidents on military aviation will reduce the combat capability of the organization concerned significantly outside enemy factors (Carretta et al., 2014). The Indonesian Naval Aviation Center as the main component of the organizers of national defence in and through the air in carrying out its duties is strongly influenced by the conditions of the defence equipment, its capital system, and most importantly influenced by the personnel who are watching it. The performance appraisal approach used in the military pilot assessment is the judgment-performance evaluation approach because it can provide maximum results for assessing pilot performance in the Indonesian Naval Aviation Center. The performance evaluation according to Jody \& Gollery (2019), based on the description of specific behaviours using dimensions, among others, as follows:

1.) Quantity of work, including the amount of work, done, the length of time used, and the number of mistakes made.

2.) Quality of work, which includes accuracy and perfection in work.

3.) Job Knowledge, which includes employee understanding of facts or factors related to jobs and skills.

4.) Creativity, namely the ideas generated and actions in solving existing problems.

5.) Teamwork, namely the ability and readiness to work together with co-workers, supervisors, and subordinates to achieve organizational goals. 
6.) The initiative, namely the enthusiasm, sincerity, and excellence of employees to carry out their duties and responsibilities.

7.) Dependability, which includes awareness of following company instructions and policies without supervision from the supervisor.

8.) Personal quality, which involves personality, leadership, friendliness, and personal integrity.

Based on the above view, the researcher uses the conceptual definition of pilot performance in the Indonesian Naval Aviation Center, which is interpreted as an outcome record resulting from a particular work function or activity during a certain period that shows how well the pilots are performing their duties. The performance of pilots in the Indonesian Naval Aviation Center can be measured by using indicators such as the quantity of work, quality of work, understanding of work procedures, creativity, cooperation, ability to delegate, initiative, and personal quality in the preparation of special assignment mission and work domain of flight. Figure 3 and Figure 4 are related to the special assignment mission according to Young (2008) and work domain of flight according to Naikar \& Sanderson (2001) for the development of pilot performance by meta-analysis as follows: 


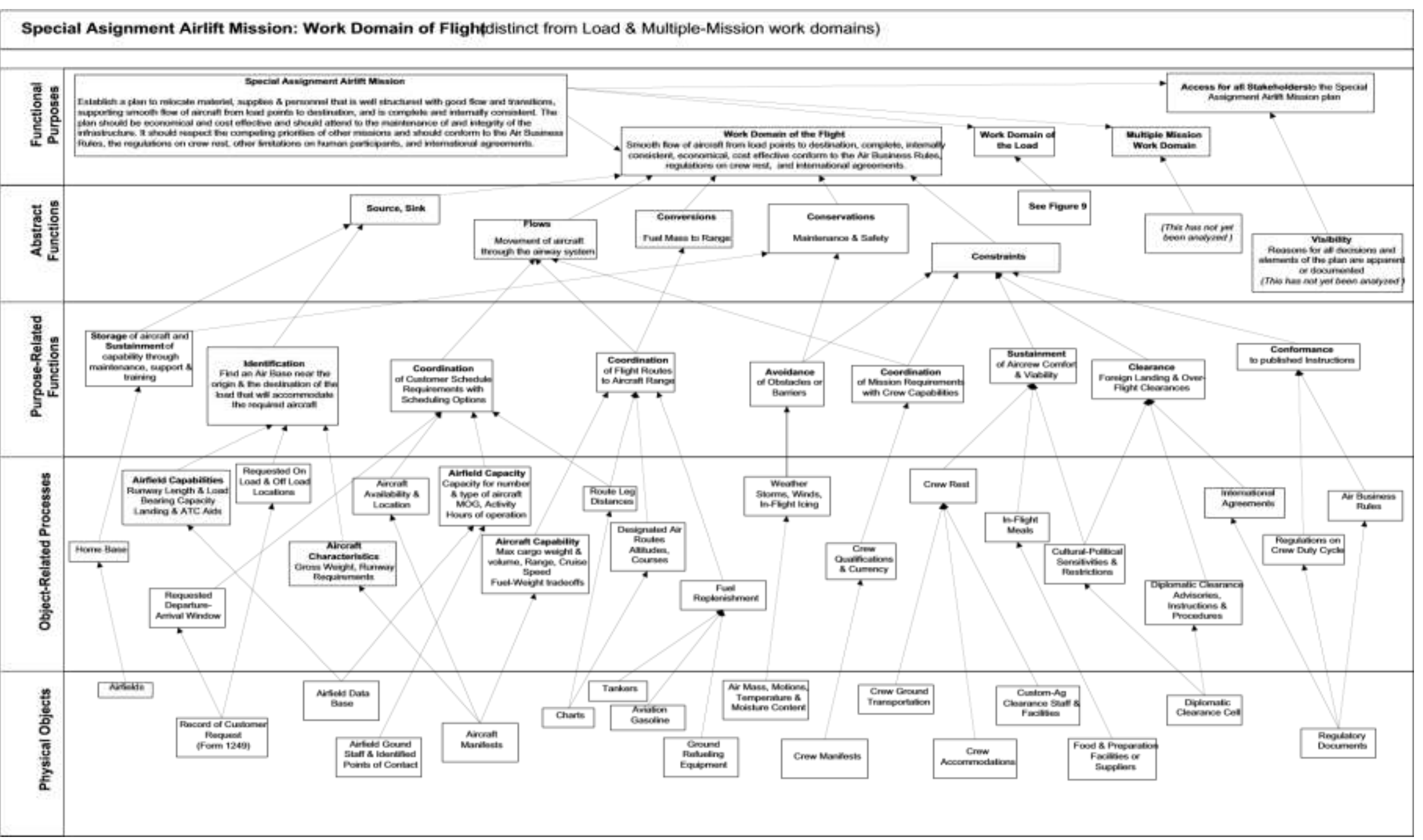

Figure 3: Special assignment mission (Source: Young, 2008) 


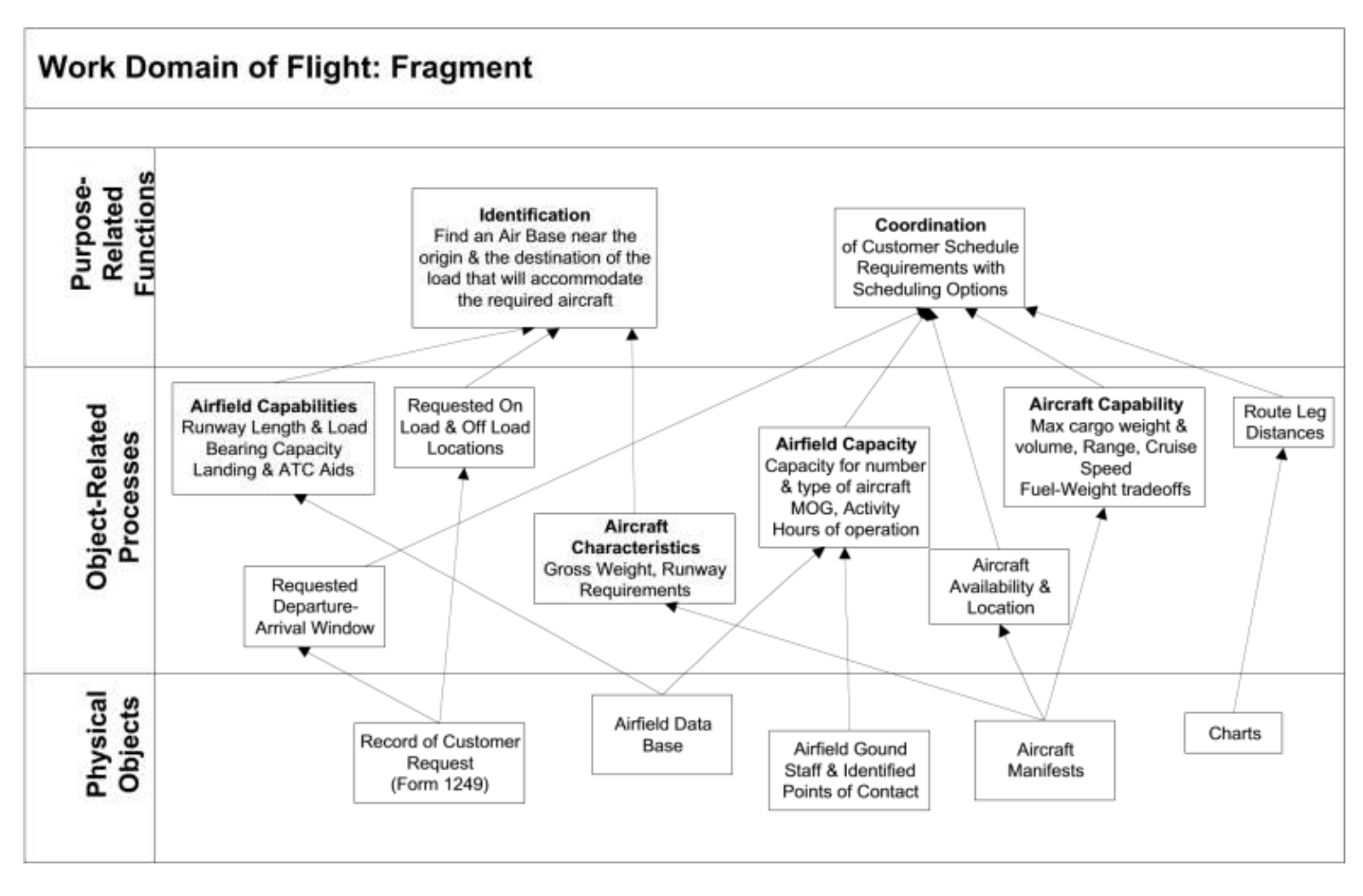

Figure 4: Scheme of work domain of flight

(Source: Naikar \& Sanderson, 2001)

(1)

\section{.}

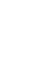




\section{Conclusion}

In the meta-analysis, the results of this study have several conclusions that are in line with the essence of personal character which is defined as the personal aspects of a worker that enables workers to achieve superior performance, where the dimensions of the personal character become five, including 1.) Openness to experience; 2.) Conscientiousness; 3.) Extraversion; 4.) Agreeableness; 5.) Neuroticism. Findings related to aspects of personal characteristics include traits, emotive, motives, value systems, attitudes, knowledge, and skills, where the personal character will produce optimal performance in the pilot of the Indonesian Naval Aviation Center.

Some recommendations need to be explained by researchers as a form of the real contribution of the results of this study to pilots in the Indonesian Naval Aviation Center, including 1.) Periodic monitoring and evaluation is needed in each training session and assignments to minimize mistakes made by pilots based on zero accident and zero mistakes; 2.) Need for assessment and skills upgrading for pilots to support their performance improvement. This research is also limited to several things, including 1.) Subjectively, this study only describes personal characteristics and performance of objects in the pilot in the Indonesian Naval Aviation Center conducted by meta-analysis method with the design of literature studies which should field study designs that can be carried out but due to the effects of the COVID-19 pandemic which is currently sweeping globally.

\section{References}

Ahn, E. \& Kang, H. (2018). Introduction to Systematic Review and Meta-Analysis. Korean Journal of Anesthesiology, 71(2), 103-112.

Bjerke, E., Smith, G., Smith, M., Christensen, C., Carney, T., Craig, P., \& Niemczyk, M. (2016). Pilot Source Study 2015: US Regional Airline Pilot Hiring Background Characteristic Changes Consequent to Public Law 111-216 and the FAA First Officer Qualifications Rule. Journal of Aviation Technology and Engineering, 5(2/1). DOI: http://dx.doi.org/10.7771/2159-6670.1133 
Carretta, T., Teachout, M., Ree, M., Barto, E., King, R. \& Michaels, C. (2014). Consistency of the Relations of Cognitive Ability and Personality Traits to Pilot Training Performance. The International Journal of Aviation Psychology, 24(4), 247-264.

Castaneda, M. A. (2007). A Big Five Profile of The Military Pilot: A Meta-Analysis. Published Thesis. Department of Psychology. College of Arts and Sciences the University of West Florida.

Chang, M. C., Lee, T. H. \& Lung, F. W. (2018). Personality Characteristics of Fighter Pilots and Ground Personnel. Military Psychology, 30, 70-78. DOI: https://dx.doi.org/10.1080/08995605.2017.1420977

Cox, B. D., Schmidt, L. L., Slack, K. J. \& Foster, T. C. (2013). Assessment and Selection of Military Aviators and Astronauts. In C. H. Kennedy \& G. G. Kay (Eds.), Aeromedical psychology (p. 17-36). Ashgate Publishing Ltd.

Crocetti, E. (2016). Systematic Reviews with Meta-Analysis: Why, When, and How?. Emerging Adulthood, 4(1), 3-18. DOI: http://dx.doi.org/10.1177/2167696815617076

Gao, Y., \& Kong, S. (2016). Personality Types of Pilot Students: A Study of an Australian Collegiate Aviation Program. International Journal of Aviation, Aeronautics, and Aerospace, 3(3). https://doi.org/10.15394/ ijaaa.2016.1130

Glicksohn, J, \& Naor-Ziv, R. (2017). Personality Profiling of Pilots: Traits and Cognitive Style. International Journal of Personality Psychology, 2(1), 7-14.

Gogtay, N. J. \& Thatte, U. M. (2017). An Introduction to Meta-Analysis. Journal of the Association of Physicians of India, 65, 78-85.

Judy, A. \& Gollery, T. (2019). U.S. Navy Pilot Competence: An Exploratory Study of Flight Simulation Training Versus Actual Aircraft Training. Journal of Applied Social Science Research and Practice, 1, 4-33.

Makarowski, R., Makarowski, P., Smolicz, T. \& Plopa, M. (2016). Risk Profiling of Airlines Pilots: Experience, Temperamental Traits and Aggression. Journal of Air Transport Management, 57, 298-306. DOI: http://dx.doi.org/10.1016/j.jairtraman.2016.08.013

Maroco, J. \& Ribeiro, R. B. (2013). Selection of Air Force Pilot Candidates: A Case Study on the Predictive Accuracy of Discriminant Analysis, Logistic Regression, and Four Neural Network Types. The International Journal of Aviation Psychology, 23(2), 130152. DOI: http://dx.doi.org/10.1080/10508414.2013.772837

Marrón, D. M. (2018). Human Factors in Aviation: CRM (Crew Resource Management). Psychologist Papers, 39(3), 191-199. DOI: https://dx.doi.org/10.23923/pap.psicol2018.2870

Murray, E., Berkowitz, M. \& Lerner, R. (2019). Leading With and for Character: The Implications of Character Education Practices for Military Leadership. Journal of Character \& Leadership Development, 6(1), 33-42.

Naikar, N \& Sanderson, P. M. (2001). Using Work Domain Analysis to Evaluate Design Proposals for Complex Sociotechnical Systems. Human Factors, 43, 529-542.

Packard, G. (2019). Moving Beyond the Status Quo: Leveraging the Leadership, Teamwork, \& Organizational Development Outcome at the U.S. Air Force Academy to Improve Leadership Education and Training. Journal of Character \& Leadership Development, 6(1), 9-19.

Robertson, M. \& Putnam, A. (2008). Personality Types of Student Pilots Admitted to the Aviation Flight Program at Southern Illinois University Carbondale. Collegiate Aviation Review, 26(1), 111-124.

Rose, M. R., Barron, L. G., Carretta, T. R., Arnold, R. D. \& Howse, W. R. (2014). Early Identification of Unmanned Aircraft Pilots Using Measures of Personality and Attitude. The International Journal of Aviation Psychology, 24, 36-52. 
Smith, G., Bjerke, E., Smith, M., Christensen, C., Carney, T., Craig, P. \& Niemczyk, M. (2016). Pilot Source Study 2015: An Analysis of FAR Part 121 Pilots Hired After Public Law 111-216-Their Backgrounds and Subsequent Successes in US Regional Airline Training and Operating Experience. Journal of Aviation Technology and Engineering, 6(1), 64-89. DOI: https://dx.doi.org/10.7771/2159-6670.1140

Smith, M. O., Smith, G. M., Bjerke, E., Christensen, C., Carney, T. Q., Craig, P. A. \& Niemczyk, M. (2017). Pilot Source Study 2015: A Comparison of Performance at Part 121 Regional Airlines between Pilots Hired before the U.S. Congress Passed Public Law 111-216 and Pilots Hired after the Law's Effective Date. Journal of Aviation Technology and Engineering, 6(2), 50-79. DOI: http://dx.doi.org/10.7771/2159$\underline{6670.1151}$

Tangwe, Y. \& Shan, F. (2014). Workload-Oriented Flight Scenario for Evaluation of PilotAircraft Interaction. Procedia Engineering, 80, 656-667. DOI: http://dx.doi.org/10.1016/j.proeng.2014.09.120

Young, J. A. (2008). The Effect of Life-Stress on Pilot Performance. National Aeronautics and Space Administration. Hanover, MD: NASA Center for Aerospace Information. 